\title{
DINÂMICA DA MATÉRIA ORGÂNICA DE UM NEOSSOLO QUARTZARÊNICO DE CERRADO CONVERTIDO PARA CULTIVO EM SUCESSÃO DE SOJA E MILHETO(1)
}

\author{
Jeander Oliveira Caetano ${ }^{(2)}$, Vinícius de Melo Benites ${ }^{(3)}$, Gilson Pereira Silva ${ }^{(4)}$, Ivo \\ Ribeiro da Silva ${ }^{(5)}$, Renato Lara de Assis $^{(6)}$ \& Alberto Cargnelutti Filho ${ }^{(7)}$
}

\begin{abstract}
RESUMO
O uso e o manejo de Neossolos Quartzarênicos podem influenciar a matéria orgânica do solo (MOS), mas a magnitude dessas alterações ainda é pouco pesquisada nas condições de Cerrado. $O$ objetivo deste trabalho foi estudar as variações que ocorrem na MOS em um Neossolo Quartzarênico, por consequência da conversão da vegetação original para o uso agrícola e cultivo sequencial de soja e milheto em sucessão. Em uma área de cultivo comercial em Alto Garças, MT, foram coletadas amostras de solo nas profundidades de 0-5, 0-10, 0-20 e 0-40 cm, em talhões que estavam sob sucessão soja-milheto durante 1, 2, 6, 8 e 10 anos e, como referência da vegetação original, amostras foram tomadas em área adjacente sob Cerrado nativo. Foram determinados os teores de carbono orgânico total (COT), carbono e nitrogênio total e o teor de carbono nas frações ácidos húmicos, ácidos fúlvicos e na matéria orgânica leve (MOL), além da relação isotópica do carbono na MOS. A conversão do Cerrado para cultivo agrícola elevou o teor de COT do solo, sobretudo em razão do aporte de MOL e fragmentos de carvão. $O$ manejo desse solo com a sucessão soja-milheto, mesmo com o uso de gradagens pesadas, não causou reduções nos teores de COT, ao longo do tempo. Contudo, observou-se variação na distribuição do carbono nas diferentes frações da MOS ao longo do
\end{abstract}

(1) Parte da Dissertação de Mestrado do primeiro autor, apresentada à Universidade de Rio Verde - UniRV. Recebido para publicação em 10 de junho de 2012 e aprovado em 29 de maio de 2013.

(2) Bolsista de Desenvolvimento Científico Regional do convênio FAPEG/CNPq executado na Universidade Federal de Goiás, Campus Jataí. Programa de Pós-graduação em Agronomia. Rodovia BR 364, Km 192, nº 3.800, Parque Industrial. CEP 75801615 Jataí (GO). E-mail: jeandercaetano@gmail.com

(3) Pesquisador, Embrapa Solos. Rua Jardim Botânico, 1024, Jardim Botânico. CEP 22460-000 Rio de Janeiro (RJ). E-mail: vinicius@cnps.embrapa.br

(4) In memorian.

(5) Professor Adjunto, Departamento de Solos, Universidade Federal de Viçosa. Av. P. H. Rolfs, s/n. CEP 36571-000 Viçosa (MG). Bolsista de Produtividade em Pesquisa do CNPq 1D. E-mail: ivosilva@ufv.br

(6) Professor, Instituto Federal de Educação, Ciência e Tecnologia Goiano, Campus Iporá. Rodovia GO 060, Km 01, Zona Rural. CEP 76200-000 Iporá (GO). Bolsista de Produtividade em Pesquisa do CNPq 2. E-mail: relassis@bol.com.br

(7) Professor Adjunto, Universidade Federal de Santa Maria, Departamento de Fitotecnia, Centro de Ciências Rurais. Av. Roraima, s/n. Campus Camobi. CEP 97105-900 Santa Maria (RS). Bolsista de Produtividade em Pesquisa do CNPq 1C. E-mail: cargnelutti@pq.cnpq.br 
tempo de cultivo, indicando alterações significativas na qualidade da MOS. Notouse aumento no percentual de carbono na forma de MOL e redução dos teores de carbono na forma de ácidos fúlvicos ao longo do tempo de cultivo, sugerindo a perda seletiva dos compostos mais solúveis. A relação isotópica do carbono do solo aumentou com o tempo de cultivo, indicando maior contribuição do carbono derivado do milheto para a manutenção dos teores de MOS. Os atributos da MOS relativos à camada de $0-20 \mathrm{~cm}$ foram mais sensíveis às variações em razão do tempo de cultivo do que os mesmos atributos avaliados nas demais camadas estudadas. As variáveis relacionadas ao fracionamento da MOS evidenciaram-se mais sensíveis às variações por causa do tempo de cultivo do que simplesmente do teor de COT do solo, apresentando o potencial de uso dessas variáveis como indicadores de qualidade do solo.

Termos de indexação: Glycine max, Pennisetum glaucum, indicadores de qualidade do solo, substâncias húmicas, matéria orgânica leve, solo arenoso.

\title{
SUMMARY: DYNAMICS OF ORGANIC MATTER OF A SANDY SOIL UNDER CERRADO TURNED INTO CROPLAND CONVERTED TO SOYBEAN AND MILLET SUCCESSION
}

\begin{abstract}
The use and management of Quartzipsamments can influence soil organic matter (SOM), but the magnitude of these variations for the specific conditions in the Cerrado (savanna-like vegetation) is still poorly studied. The aim of this work was to study the variations in SOM in a Quartzipsamment, after the conversion of native vegetation to cropland (soybean-millet rotation). Soil was sampled from 0-5, 0-10, 0-20 and 0-40 cm depths of a commercial field in Alto Garças, Mato Grosso, Brazil, of plots under soybean-millet rotation in plots converted to croplands for 1, 2, 6, 8, and 10 years. Additionally, soil samples were taken from an adjacent area under native Cerrado (savanna) as a reference of the original vegetation. Total organic carbon (TOC), total C, total N, C content in humic and fulvic acids, light organic matter (LOM), and the SOM carbon isotope ratio were determined. The conversion of Cerrado to agriculture increased the soil TOC content, mainly due to the contribution of LOM and charcoal fragments. The management of this soil with soybean- millet rotation, despite the use of heavy disking, did not reduce the TOC levels over time. However a variation in the $C$ distribution in the different SOM fractions was observed over time, indicating significant changes in the SOM quality. Over time, an increase was observed in light organic matter and a reduction in $C$ contents in the form of fulvic acids, suggesting a selective loss of the more soluble $C$-compounds. The isotope ratio of soil $C$ increased with time, indicating a higher contribution of $C$ derived from millet, maintaining the SOM levels. The SOM properties in the 0-20 cm layer were more sensitive to variations as a function of cultivation time than the same properties in the other layers. Soil organic matter fractions were more sensitive to variations in function of cultivation time than the soil TOC content, showing the potential use of these variables as soil quality indicators.
\end{abstract}

Index terms: Glycine max, Pennisetum glaucum, soil quality indicators, humic substance, light organic matter, sandy soil.

\section{INTRODUÇÃO}

A região dos Cerrados do Brasil compreende aproximadamente 207 milhões de ha, com aproximadamente 127 milhões de hectares aptos para a agropecuária. Os Neossolos Quartzarênicos (RQs) ocupam 30 milhões de ha, correspondendo aproximadamente $15 \%$ da área do Cerrado. $\mathrm{O}$ aumento da demanda por commodities agrícolas no mundo e as restrições ao desmatamento ocasionaram a utilização de áreas marginais, como a exploração agrícola dos RQs na região dos Cerrados. Os RQs foram cultivados, inicialmente, no preparo convencional do solo, com utilização intensiva de grade e arado, causando a sua degradação (Batlle-Bayer et al., 2010; Frazão et al., 2010a). Mais recentemente, o uso do cultivo mínimo, do plantio direto e da integração lavoura-pecuária tem ocasionado melhor conservação de suas características em algumas regiões do Brasil (Carneiro et al., 2009; Frazão et al., 2010a,b; Sales et al., 2010). Partiu-se de um sistema altamente degradativo da matéria orgânica do solo (MOS) para outros que minimizam esse efeito. Em relação ao impacto da agricultura em RQs já existem alguns estudos no Brasil (Zinn et al., 2005b; Carneiro et al., 2009; Frazão et al., 2010a; Sales et al., 2010), sendo necessário verificar se os manejos utilizados nesses solos são sustentáveis. O seu uso intensivo influencia 
a MOS, mas essas alterações necessitam de esclarecimentos para o Cerrado, especialmente sob contínua rotação com adubos verdes.

O teor e a dinâmica da MOS são os atributos que melhor representam a qualidade do solo e podem ser alterados com as práticas de manejo (Chivenge et al., 2007). Essa dinâmica deve ter como referência os solos em condições não perturbadas, ou seja, sob vegetação nativa, já que nesses não ocorrem grandes variações no seu conteúdo, no curto prazo. Um solo de boa qualidade não deve apresentar apenas elevado teor de MOS, necessita também de um equilíbrio entre formas estáveis e mineralizáveis dessa matéria orgânica. Entre os compartimentos da MOS para avaliações qualitativas estão as substâncias húmicas, que são de ciclagem lenta, e a matéria orgânica leve, que possui ciclagem intermediária (Silva \& Mendonça, 2007).

Com a elevação da MOS ocorre aumento da CTC dos solos de Cerrado (Araújo et al., 2007; Campos et al., 2011), sendo essa essencial para reter os cátions básicos e aumentar a fertilidade do solo. Esse efeito é mais pronunciado nos RQs (Frazão et al., 2008), onde a predisposição ao processo de lixiviação de cátions e perda de MOS é maior (Carneiro et al., 2009). Assim, o uso sustentável desses solos depende da manutenção ou até mesmo do aumento gradativo dos teores de MOS, podendo ser obtido, por exemplo, com a utilização de cobertura vegetal constante do solo.

A rápida decomposição de palhada na região de Cerrado dificulta a manutenção de uma cobertura uniforme na superfície do solo e dessa forma a escolha de espécies mais resistentes à decomposição de seus resíduos assume importância. A utilização de plantas de cobertura, de crescimento rápido, antecipado ao plantio de verão, vem assumindo importância em regiões dos Cerrados (Campos et al., 2011), onde as condições climáticas limitam o acúmulo e a manutenção de cobertura durante longo período. Nessas condições, vem destacando-se o milheto, que, além dessa vantagem, tem alta produção de matéria seca, sistema radicular profundo e abundante (Gonçalves et al., 2006), alta capacidade de reciclagem de nutrientes do solo (Boer et al., 2007), tolerância à seca e é bem adaptado a solos arenosos (Marteau et al., 2011).

O objetivo deste trabalho foi estudar as variações que ocorrem na MOS em um Neossolo Quartzarênico, por consequência da conversão da cobertura com vegetação original para o uso agrícola e cultivo sequencial de soja e milheto em sucessão.

\section{MATERIAL E MÉTODOS}

A área em estudo está localizada em Alto Garças, MT ( $16^{\circ} 50^{\prime} 34,4^{\prime \prime} \mathrm{S}$ e $53^{\circ} 50^{\prime} 23,2^{\prime \prime} \mathrm{W} ; 700 \mathrm{~m}$ de altitude). O clima é do tipo Aw na classificação de
Köppen, com temperatura média de $23,3{ }^{\circ} \mathrm{C}$ e precipitação pluvial média de $1.827 \mathrm{~mm}$. O solo foi classificado como Neossolo Quartzarênico órtico latossólico - RQ (Embrapa, 2006).

As áreas de estudo foram previamente selecionadas a partir do histórico de uso e das análises de solo existentes na propriedade, selecionando-se somente aquelas que foram convertidas diretamente para agricultura a partir do Cerrado nativo e que apresentassem a maior proximidade possível quanto à textura do solo. As áreas amostradas estavam sob uso agrícola para a produção de soja, sucedendo milheto sob diferentes áreas de cultivo e uma área sob Cerrado nativo. Para representar as diferentes áreas de cultivo, selecionaram-se glebas de 306 ha (área de cultivo com um ano - AC1), 169 ha (área de cultivo com dois anos - AC2), 50 ha (área de cultivo com seis anos - AC6), 140 ha (área de cultivo com oito anos AC8) e 200 ha (área de cultivo com 10 anos - AC10), conforme figura 1 . A área estudada apresentou textura arenosa e a caracterização química e granulométrica encontra-se no quadro 1 (Caetano, 2006). As amostragens foram realizadas em áreas convertidas para lavouras, a partir da derrubada e queima do Cerrado. Essas áreas de cultivo foram contidas em uma delimitação com raio máximo de $10 \mathrm{~km}$. Para a abertura dessas, no primeiro ano de cultivo, fez-se uso de grades aradoras de $32 ", 28$ " e 22 " para limpeza da área e incorporação de calcário e milheto (Figura 1). Após esse preparo inicial, realizou-se a semeadura a lanço de $15 \mathrm{~kg} \mathrm{ha}^{-1}$ de milheto e, a partir dessa abertura até o ano de 2001, utilizou-se da mesma quantidade de sementes dos milhetos BN2 e BRS1501 incorporadas com grade leve de 22". A partir de 2002, efetuou-se a semeadura dos milhetos ADR300 e ADR500 de duas formas diferentes. Após a aplicação superficial de $20 \mathrm{~kg} \mathrm{ha}^{-1}$ de sementes com distribuidor, aplicou-se o correntão para a sua incorporação. Além desse sistema, utilizou-se da sobressemeadura com a distribuição de $25 \mathrm{~kg} \mathrm{ha}^{-1} \mathrm{de}$ sementes por aeronave. Nessas áreas, realizou-se o cultivo de soja no verão, para produção de sementes e grãos, e no inverno, o milheto foi usado constantemente como planta de cobertura e produção de sementes. $\mathrm{O}$ milheto foi semeado, após a colheita da soja, no final do período chuvoso (fevereiro a maio) e, antes da semeadura da soja, no início das chuvas (setembro a novembro). Assim, efetuaram-se o plantio convencional na abertura de todas as áreas de cultivo, com o uso das grades; o cultivo mínimo nas áreas cultivadas entre o período de 1994 a 2001, com o uso da grade leve para incorporar milheto e calcário; e, a partir de 2001, o plantio direto, já que o milheto foi incorporado com correntão e com o uso da sobressemeadura.

Os tratamentos foram constituídos por cinco áreas sob diferentes cultivo (AC1, AC2, AC6, AC8 e AC10) e uma área com Cerrado nativo stricto sensu. Para as análises de MOS, amostras de solos foram coletadas em outubro de 2004, antes da semeadura da soja, nas profundidades de $0-5,5-10,10-20$ e $20-40 \mathrm{~cm}$, na entrelinha da semeadura anterior de soja (safra 2003/ 
Quadro 1. Caracterização granulométrica e química de um Neossolo Quartzarênico em diferentes áreas de cultivo de soja e milheto, na profundidade de $0-20 \mathrm{~cm}$

\begin{tabular}{|c|c|c|c|c|c|c|}
\hline \multirow{2}{*}{ Atributo } & \multicolumn{6}{|c|}{ Área de cultivo ${ }^{(1)}$} \\
\hline & Cerrado & AC1 & AC2 & AC6 & AC8 & AC10 \\
\hline Areia $\left(\mathrm{g} \mathrm{kg}^{-1}\right)$ & 913,32 & 848,33 & 849,75 & 817,31 & 906,69 & 861,30 \\
\hline Silte $\left(\mathrm{g} \mathrm{kg}^{-1}\right)$ & 31,18 & 50,15 & 48,72 & 61,28 & 24,58 & 96,63 \\
\hline Argila $\left(\mathrm{g} \mathrm{kg}^{-1}\right)$ & 55,50 & 101,52 & 101,53 & 121,41 & 68,73 & 42,07 \\
\hline $\mathrm{pH}\left(\mathrm{CaCl}_{2}\right)$ & 4,05 & 5,55 & 5,92 & 5,70 & 5,70 & 6,19 \\
\hline $\mathrm{Al}^{3+}\left(\mathrm{cmol}_{\mathrm{c}} \mathrm{dm}^{-3}\right)$ & 0,94 & 0,00 & 0,00 & 0,00 & 0,00 & 0,00 \\
\hline Saturação por alumínio (\%) & 93,17 & 0,00 & 0,00 & 0,00 & 0,00 & 0,00 \\
\hline $\mathrm{Ca}^{2+}\left(\mathrm{cmol}_{\mathrm{c}} \mathrm{dm}^{-3}\right)$ & $<0,01$ & 2,11 & 1,66 & 1,99 & 2,01 & 2,10 \\
\hline $\mathrm{Mg}^{2+}\left(\mathrm{cmol}_{\mathrm{c}} \mathrm{dm}^{-3}\right)$ & 0,04 & 0,64 & 0,41 & 0,68 & 0,83 & 0,82 \\
\hline $\mathrm{K}^{+}\left(\mathrm{cmol}_{\mathrm{c}} \mathrm{dm}^{-3}\right)$ & 0,03 & 0,12 & 0,16 & 0,15 & 0,12 & 0,12 \\
\hline Saturação por bases (\%) & 1,97 & 54,99 & 61,50 & 75,50 & 73,32 & 83,19 \\
\hline $\mathrm{CTC}_{\text {efetiva }}\left(\mathrm{cmol}_{\mathrm{c}} \mathrm{dm}^{-3}\right)$ & 1,00 & 3,00 & 2,32 & 2,93 & 3,07 & 3,08 \\
\hline $\mathrm{CTC}_{\text {total }}\left(\mathrm{cmol}_{\mathrm{c}} \mathrm{dm}^{-3}\right)$ & 3,43 & 5,18 & 3,60 & 3,75 & 4,04 & 3,64 \\
\hline $\operatorname{MOS}\left(\mathrm{g} \mathrm{kg}^{-1}\right)$ & 8,35 & 11,90 & 8,86 & 10,90 & 9,86 & 9,64 \\
\hline $\mathrm{N}$ total $\left(\mathrm{g} \mathrm{kg}^{-1}\right)$ & 0,35 & 0,43 & 0,38 & 0,50 & 0,47 & 0,46 \\
\hline $\mathrm{P}$ disponível $\left(\mathrm{mg} \mathrm{dm}^{-3}\right)$ & 0,96 & 8,86 & 9,68 & 9,26 & 8,07 & 27,51 \\
\hline
\end{tabular}

(1) AC1: área de cultivo com um ano, AC2: área de cultivo com dois anos, AC6: área de cultivo com seis anos, AC8: área de cultivo com oito anos, e AC10: área de cultivo com 10 anos.

2004). Coletaram-se quatro repetições por área, com 20 subamostras por repetição, distribuídas aleatoriamente por cada área. A partir dos dados obtidos, calcularam-se os valores relativos às camadas de 0-5, 0-10, 0-20 e 0-40 cm, pelas médias ponderadas das camadas amostradas, com o objetivo de definir a camada mais representativa das variações da quantidade e qualidade da MOS nesse sistema. Foram montadas quatro matrizes de dados, cada uma com os valores dos atributos da MOS relativos às camadas de 0-5, 0-10, 0-20 e 0-40 cm.

Determinou-se o teor de carbono orgânico total (COT), a partir de amostras de TFSA maceradas (<0,210 mm) (Yeomans \& Bremner, 1988), assim como o teor de nitrogênio total (NT) (Bremner \& Mulvaney, 1982). O fracionamento físico por densidade foi efetuado de acordo com Sohi et al. (2001), coletando-se a fração leve livre da matéria orgânica do solo (MOL) em peneira de 0,25 mm. Esse material foi, a seguir, seco a $65{ }^{\circ} \mathrm{C}$ por $72 \mathrm{~h}$. Os teores de carbono $\left(\mathrm{C}_{\mathrm{MOL}}\right)$ e nitrogênio da MOL $\left(\mathrm{N}_{\mathrm{MOL}}\right)$ foram determinados por via combustão seca (CHNS/O) em analisador elementar, modelo Perkin Elmer, PE-2400 Séries II. Foi calculado o percentual do carbono da MOL $\left(\% \mathrm{C}_{\mathrm{MOL}}\right)$, em relação à soma das frações húmicas. Os teores de carbono total do solo (CT) também foram determinados em analisador elementar, calculandose a relação CT/COT.

Procedeu-se ao fracionamento das substâncias húmicas por solubilidade diferencial em meio ácido ou alcalino (Benites et al., 2003). Obtiveram-se os valores absolutos do carbono das frações ácido húmico $\left(\mathrm{C}_{\mathrm{AH}}\right)$, ácido fúlvico $\left(\mathrm{C}_{\mathrm{AF}}\right)$ e não solúvel em meio alcalino
$\left(\mathrm{C}_{\mathrm{NS}}\right)$. O $\mathrm{C}_{\mathrm{MOL}}$ foi subtraído do $\mathrm{C}_{\mathrm{NS}}$, resultando na fração humina $\left(\mathrm{C}_{\mathrm{H}}\right)$, uma vez que a MOL é coextraída com a humina por esse método (Benites et al., 2003). Foi calculado o percentual de cada fração em relação à soma $\left(\% \mathrm{C}_{\mathrm{AH}}, \mathrm{C}_{\mathrm{AF}} \mathrm{e} \% \mathrm{C}_{\mathrm{H}}\right)$ e relação $\mathrm{C}_{\mathrm{AH}} / \mathrm{C}_{\mathrm{AF}}$. $\mathrm{O}$ fator de recuperação do método foi obtido pelo somatório de $\mathrm{C}_{\mathrm{AH}}, \mathrm{C}_{\mathrm{AF}}$ e $\mathrm{C}_{\mathrm{H}}$, em relação ao COT.

Amostras de solo maceradas $(<0,149 \mathrm{~mm})$ foram utilizadas para determinar a abundância natural do ${ }^{13} \mathrm{C}\left({ }^{13} \mathrm{C} /{ }^{12} \mathrm{C}\right)$, em espectrômetro de massa de razão isotópica de fluxo contínuo (20-20 ANCA-GSL, Sercon, Crewe, UK). A razão isotópica do $C\left(\delta^{13} C\right)$ foi referenciada ao padrão Pee Dee Belemnite e expressa em partes por mil (\%o), com precisão analítica de $0,3 \%$ :

$$
\begin{aligned}
& \delta^{13} \mathrm{C}=\left[\left({ }^{13} \mathrm{C} / 12 \mathrm{C} \text { amostra }{ }^{-{ }^{13} \mathrm{C} / 12} \mathrm{C} \text { padrão }\right) /\right. \\
& \left.{ }^{13} \mathrm{C} / 12 \mathrm{C} \text { padrão }\right] \text { x } 1000
\end{aligned}
$$

As médias dos atributos da MOS em cada tratamento foram comparadas, duas a duas, dentro de cada profundidade, por meio do teste não paramétrico U de Mann-Whitney, a $5 \%$, utilizandose o programa Statistica 7 (Statsoft Inc., 2008).

\section{RESULTADOS E DISCUSSÃO}

\section{Identificação da camada do solo mais sensível às alterações na MOS}

Para cada atributo, houve uma camada onde a variabilidade, por causa do tempo de cultivo, foi melhor evidenciada (Quadro 2). Nas camadas de 0-10, 0-20 e 
0-40 cm, observou-se variabilidade no teor de COT em razão dos tratamentos, enquanto na camada de 0 5 cm isso não ocorreu (Quadro 2). Freixo et al. (2002b) obtiveram resultados diferentes aos encontrados neste trabalho, quando observaram diferença significativa nos teores de COT somente nas camadas até $10 \mathrm{~cm}$ de profundidade de um Latossolo Vermelho argiloso sob uso agrícola. Corazza et al. (1999) estudaram perfis de Latossolo Vermelho argiloso e muito argiloso sob seis sistemas de manejo; entre eles, preparo com arado de discos e plantio direto comparados com vegetação nativa de Cerrado. Esses autores verificaram que as maiores alterações nos teores de COT nos perfis ocorreram na camada de $0-20 \mathrm{~cm}$ e, a partir dessa profundidade, a tendência foi semelhante para todos os sistemas, decrescendo com a profundidade. Provavelmente, a maior homogeneidade das características da camada superficial, observada por esses autores, foi causada pelo uso de sucessivas gradagens.

Os teores de NT variaram apenas nas camadas até $20 \mathrm{~cm}$ de profundidade (Quadro 2), em razão principalmente do seu aporte pela decomposição da palhada de soja pelos sucessivos cultivos, da mesma forma que observado por Mascarenhas et al. (2011). A relação COT/NT refletiu melhor as diferenças nessas mesmas camadas, indicando também a ausência de diferenças para a camada de 0-40 cm. Quanto às frações húmicas, as variações nos teores de humina foram mais significativas na camada de $0-5 \mathrm{~cm}$, refletindo a sua baixa mobilidade, mesmo em um RQ. Os teores nas frações ácidos húmicos e ácidos fúlvicos variaram em todas as camadas, com menor significância de $0-5 \mathrm{~cm}$. Por causa da baixa retenção de compostos orgânicos pelos RQs, ocorre naturalmente a lixiviação daqueles mais solúveis para as subcamadas, sendo intensificada pelo manejo. De maneira geral, a camada de $0-20 \mathrm{~cm}$ de profundidade foi a mais representativa para as variações das análises aqui avaliadas; por isso, adotou-se essa como padrão para o estudo dos atributos da MOS. Esses resultados podem estar relacionados à homogeneização das camadas superficiais do solo, ocasionada pela gradagem profunda (até $30 \mathrm{~cm}$ ) nos primeiros anos de cultivo, com a incorporação da vegetação nativa, e da gradagem leve (até $20 \mathrm{~cm}$ ), para introdução de milheto e calcário (Figura 1).

A partir dessas observações, a camada de 0-20 cm foi escolhida para a comparação entre os tratamentos para todos os atributos estudados.

\section{Teores de carbono, de nitrogênio e das frações húmicas, na camada de $0-20 \mathrm{~cm}$ de profundidade}

As áreas estudadas apresentaram em média teor de carbono orgânico total (COT), nos primeiros $20 \mathrm{~cm}$ de profundidade de 5,75 $\mathrm{g} \mathrm{kg}^{-1}$ (Quadro 3). Esse teor de COT é considerado muito baixo e é típico dos Neossolos Quartzarênicos existentes no Cerrado (Zinn et al., 2005a,b; 2007; Carneiro et al., 2009; Frazão et al., 2010a). A média do teor de carbono total (CT) foi de $7,15 \mathrm{~g} \mathrm{~kg}^{-1}, 20 \%$ superior ao teor de COT. Essa diferença ocorre pela presença de compostos orgânicos de alta recalcitrância, não oxidados pelo método químico, como carvões e fragmentos vegetais de maior resistência, e pela presença de carbonatos residuais da utilização de doses elevadas de calcário de baixo PRNT. Os teores de NT apresentaram média de 0,43 $\mathrm{g} \mathrm{kg}^{-1}$; a relação COT/NT média foi de 13,55.

A soma do teor de $\mathrm{C}$ nas frações húmicas apresentou correlação significativa com o teor de COT (Figura 2a), e o fator de recuperação do método de fracionamento quantitativo de substâncias húmicas variou entre 86 e $104 \%$, dentro do limite aceitável para o método (Benites et al., 2003). A fração húmica não extraível apresentou a melhor correlação com os teores de COT $\left(r^{2}=0,92 ; p<0,001\right)$ (Figura 2b). Essa fração compreende, além da humina propriamente dita, também a matéria orgânica leve (MOL), pois no fracionamento utilizado não houve a sua extração prévia (Benites et al., 2003). Após o $\mathrm{C}_{\mathrm{H}}$, o $\mathrm{C}_{\mathrm{MOL}}$ foi o que melhor se correlacionou com os teores de COT $\left(\mathrm{r}^{2}=0,65 ; \mathrm{p}<0,001\right)$ (Figura $\left.2 \mathrm{c}\right)$. Isso indicou a ocorrência de aportes de MOL, em razão da presença de carvão nas áreas de Cerrado e de abertura, ou

Quadro 2. Significância do teste de Mann-Whitney para carbono orgânico total (COT), carbono total (CT), relação CT/COT, razão isotópica do $C\left({ }^{13} \mathrm{C}\right)$, nitrogênio total $(\mathrm{NT})$, relação COT/NT, carbono das frações não extraível $\left(\mathrm{C}_{\mathrm{H}}\right)$, ácido húmico $\left(\mathrm{C}_{\mathrm{AH}}\right)$, ácido fúlvico $\left(\mathrm{C}_{\mathrm{AF}}\right)$, relação entre frações ácidos húmicos e ácidos fúlvicos $\left(\mathrm{C}_{\mathrm{AH}} / \mathrm{C}_{\mathrm{AF}}\right)$, carbono da matéria orgânica leve $\left(\mathrm{C}_{\mathrm{MOL}}\right)$ e relação entre carbono e nitrogênio da matéria orgânica leve $\left(\mathbf{C} / \mathbf{N}_{\mathrm{MOL}}\right)$ de um Neossolo Quartzarênico, em diferentes áreas de cultivo de soja e milheto, em quatro profundidades de amostragem

\begin{tabular}{ccccccccccccc}
\hline Prof. & $\mathbf{C O T}$ & $\mathbf{C T}$ & $\mathbf{C T} / \mathbf{C O T}$ & $\boldsymbol{\delta}^{13} \mathbf{C}$ & $\mathbf{N T}$ & $\mathbf{C O T} / \mathbf{N T}$ & $\mathbf{C}_{\mathbf{H}}$ & $\mathbf{C}_{\mathbf{A H}}$ & $\mathbf{C}_{\mathbf{A F}}$ & $\mathbf{C}_{\mathbf{A H}} / \mathbf{C}_{\mathbf{A F}}$ & $\mathbf{C}_{\mathbf{M O L}}$ & $\mathbf{C} / \mathbf{N}_{\mathbf{M O L}}$ \\
\hline $\mathrm{cm}$ & & & & & & & & & & & & \\
$0-5$ & $\mathrm{~ns}$ & $* *$ & $* *$ & $* * *$ & $*$ & $* * *$ & $* * *$ & $*$ & $* *$ & $* * *$ & $* * *$ & $* * *$ \\
$0-10$ & $*$ & $* * *$ & $* * *$ & $* * *$ & $*$ & $* * *$ & $\mathrm{~ns}$ & $* *$ & $* * *$ & $* * *$ & $* * *$ & $* * *$ \\
$0-20$ & $* *$ & $* * *$ & $*$ & $* * *$ & $*$ & $* * *$ & $*$ & $* *$ & $* * *$ & $* * *$ & $* * *$ & $* * *$ \\
$0-40$ & $* *$ & $* * *$ & $*$ & $* *$ & $\mathrm{~ns}$ & $\mathrm{~ns}$ & $\mathrm{~ns}$ & $* *$ & $* * *$ & $* * *$ & $* * *$ & $* * *$ \\
\hline
\end{tabular}

***: $\mathrm{p}<0,001, * *: \mathrm{p}<0,01, *: \mathrm{p}<0,05$ e ns: não significativo. 


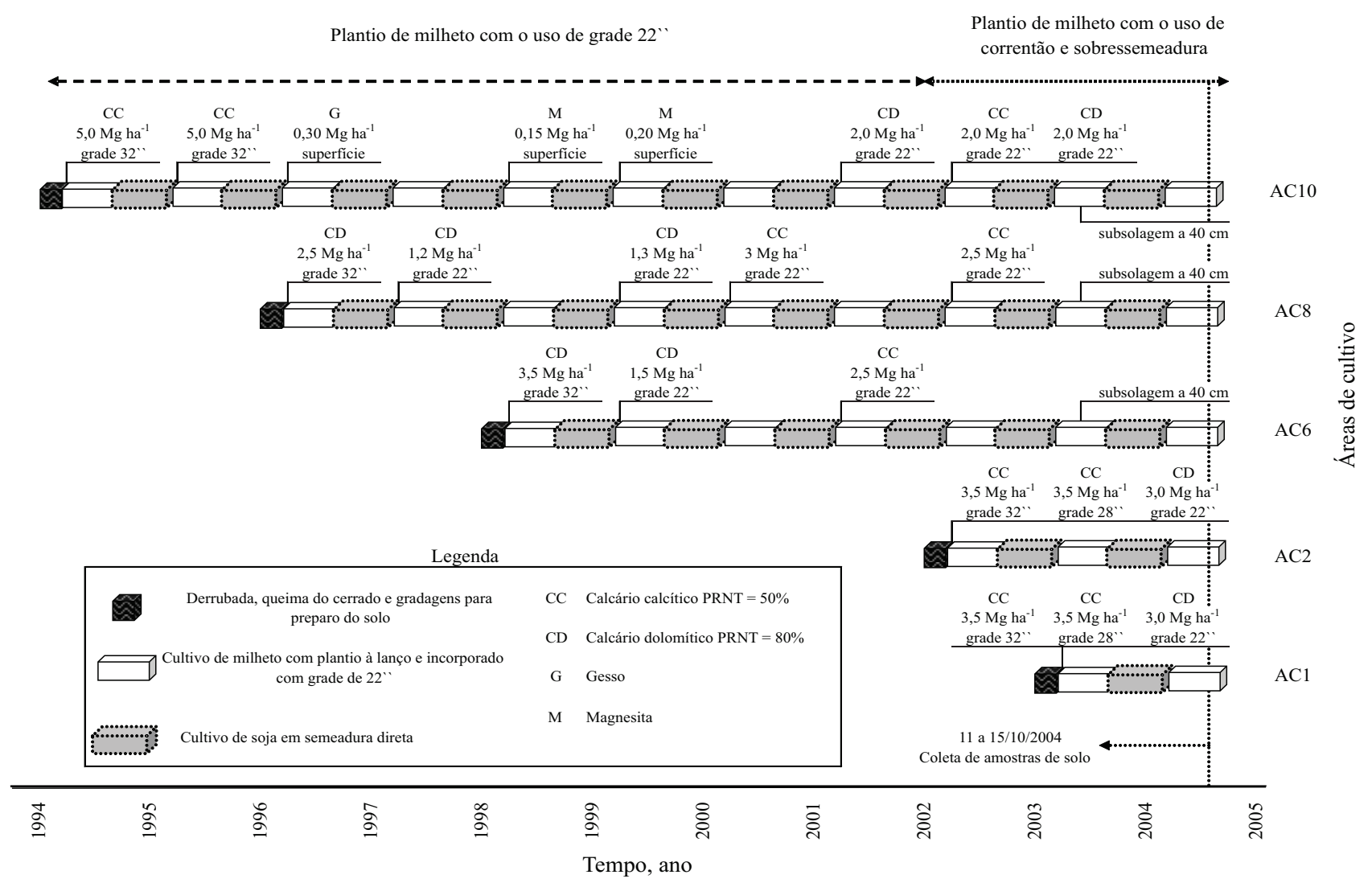

Figura 1. Esquema representativo do histórico das áreas de cultivo com um ano (AC1), dois anos (AC2), seis anos (AC6), oito anos (AC8) e 10 anos (AC10), em Alto Garças, MT.

resíduos vegetais dos sucessivos cultivos. $\mathrm{O} \mathrm{C}_{\mathrm{AH}}$ correlacionou-se melhor com os teores de COT $\left(\mathrm{r}^{2}=\right.$ 0,$52 ; \mathrm{p}<0,001$ ) (Figura $2 \mathrm{~d}$ ) do que o $\mathrm{C}_{\mathrm{AF}}$, refletindo a condição de maior estabilidade e menor mobilidade dessa fração em relação às demais. A menor correlação da $\mathrm{C}_{\mathrm{AF}}\left(\mathrm{r}^{2}=0,22 ; \mathrm{p}<0,001\right)$ (Figura $2 \mathrm{e}$ ) pode ser consequente de sua alta solubilidade e mobilidade no solo.

\section{Variações na MOS na conversão de Cerrado para sistemas de cultivo agrícola}

Utilizando-se a área de Cerrado nativo como referência, observou-se que a conversão do solo de vegetação nativa para agricultura elevou o teor de COT na camada de $0-20 \mathrm{~cm}$, no primeiro ano de cultivo (Quadro 3). A incorporação de resíduos vegetais após o desmatamento e a aplicação de corretivos e fertilizantes são fatores que mantêm ou incrementam o COT, em áreas de RQ nos primeiros anos de implantação (Frazão et al., 2010b). A elevação do COT relaciona-se ao aumento do $\mathrm{C}$ da fração MOL, composto principalmente de carvão resultante da queima dos restos culturais do Cerrado nativo. Substâncias húmicas e MOL originadas de carvão são encontradas em solos submetidos à queima, sendo relativamente estáveis e responsáveis por manter níveis elevados da MOS (Jantalia et al., 2007).
O solo sob Cerrado nativo apresentou valor de $\delta^{13} \mathrm{C}$ de $-21,15 \%$ na camada de $0-20 \mathrm{~cm}$ (Quadro 3), próximo ao valor de $-20,00 \%$ encontrado para solos de Cerrado em Minas Gerais (Wilcke \& Lilienfein, 2004) e do valor de $-23,00$ a $-25,00 \%$, verificado para os do Distrito Federal (Jantalia et al., 2007). Plantas arbóreas de Cerrado apresentam rota fotossintética C3, com valores ao redor de $-28,70 \%$, enquanto as gramíneas são na sua maioria da rota $\mathrm{C} 4$, com valores médios de $\delta^{13} \mathrm{C}$ de $-13,10 \%$ (Wilcke \& Lilienfein, 2004). Portanto, no solo sob Cerrado deste estudo havia contribuição substancial de gramíneas para a MOS, que, embora citada como tendo menor aporte de biomassa (11\%), contribuem com até $50 \%$ do COT do solo na região do Cerrado (Wilcke \& Lilienfein, 2004). Logo após a conversão para cultivo agrícola na $\mathrm{AC} 1$, a $\delta^{13} \mathrm{C}$ embora se apresentando significativamente semelhante, passou a ser mais negativa $(-23,76 \%$ ), indicando a maior participação na MOS de $\mathrm{C}$ derivado de plantas C3. Provavelmente, esse material é derivado dos resíduos da vegetação nativa, pois se situam nos intervalos das avaliações observadas por Jantalia et al. (2007). Apesar da presença de gramíneas C4 na área nativa, essas tiveram pouca influência sobre a $\delta^{13} \mathrm{C}$ após sua incorporação. Os dados de $\delta^{13} \mathrm{C}$ podem, portanto, estar refletindo em maior proporção a presença de compostos orgânicos mais recalcitrantes derivados de plantas C3 e também a presença de 
material parcialmente carbonizado pela queima de restos vegetais do Cerrado, durante a fase inicial de conversão.

A distribuição da porcentagem relativa de $\mathrm{C}$ nas frações húmicas demonstrou que a conversão do Cerrado para agricultura modificou a $\% \mathrm{C}_{\mathrm{MOL}} \mathrm{e} \% \mathrm{C}_{\mathrm{H}}$, na camada de $0-20 \mathrm{~cm}$ (Figura 3 ). A $\% \mathrm{C}_{\mathrm{MOL}}$ elevou-se em 2,5 vezes e a $\% \mathrm{C}_{\mathrm{H}}$ reduziu-se em 1,8 vez, em relação ao solo sob Cerrado. Os valores do $\mathrm{C}_{\mathrm{MOL}}$, nessa camada, também elevaram-se em 3,7 vezes na $\mathrm{AC} 1$ (Quadro 3). Observou-se alteração qualitativa na MOL, com redução da relação $\mathrm{C} / \mathrm{N}_{\mathrm{MOL}}$ na profundidade de
0-20 cm, sugerindo a mineralização de compostos alifáticos, ricos em $\mathrm{C}$, que até então estavam protegidos nos solos sob Cerrado (Quadro 3). $\mathrm{O} \% \mathrm{C}_{\mathrm{AH}}$ e $\% \mathrm{C}_{\mathrm{AF}}$ não sofreram alterações significativas na conversão para cultivo, nessa camada (Figura 3).

\section{Variações na MOS ao longo do tempo de cultivo agrícola}

$\mathrm{O}$ incremento inicial nos teores de COT na AC1, na camada de $0-20 \mathrm{~cm}$, foi seguido por um rápido decréscimo na $\mathrm{AC2}$, atingindo níveis semelhantes ao solo sob Cerrado (Quadro 3). Isso pode ter ocorrido
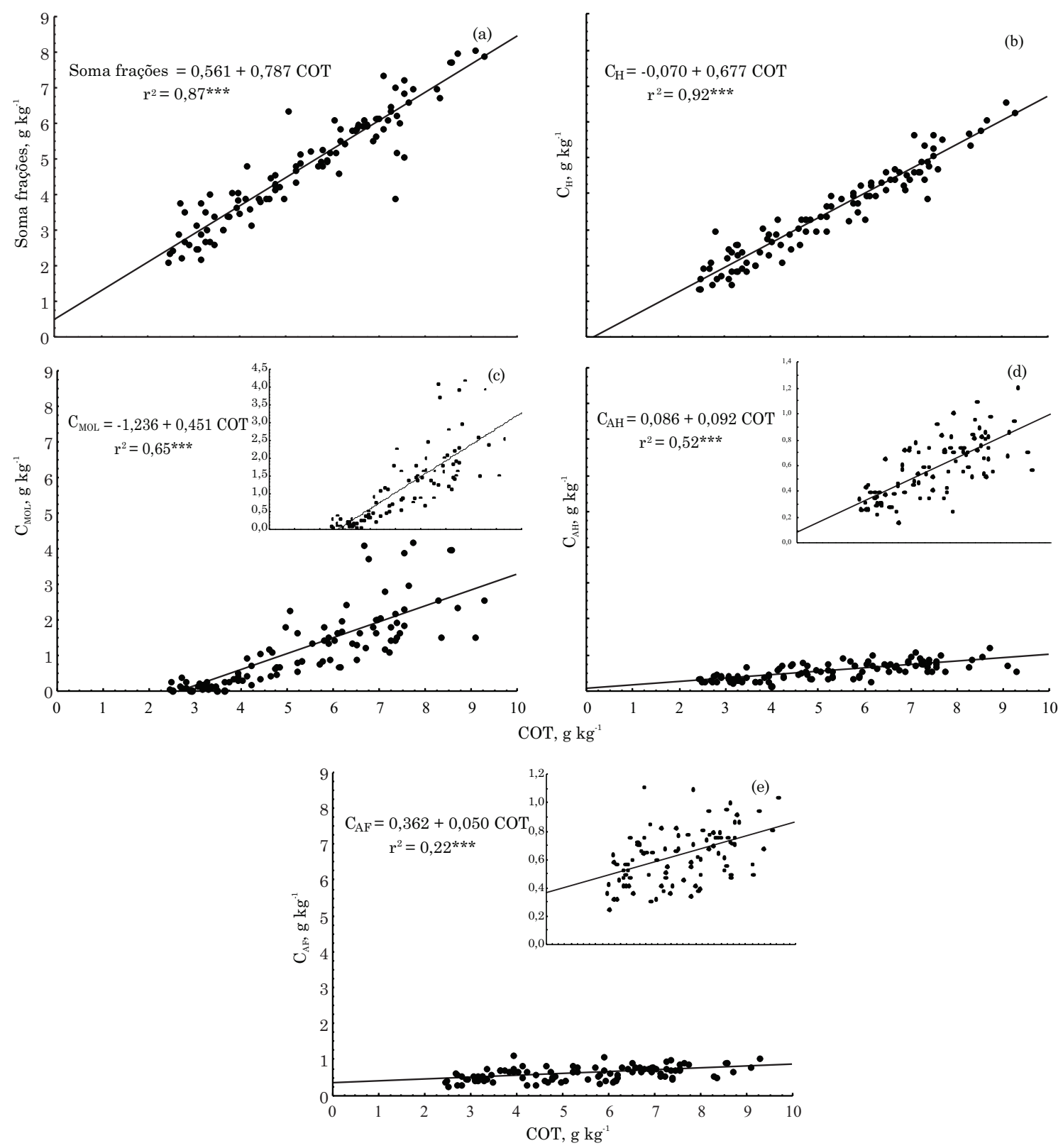

Figura 2. Fator de recuperação do método (Soma frações $=\mathrm{C}_{\mathrm{H}}+\mathrm{C}_{\mathrm{AH}}+\mathrm{C}_{\mathrm{AF}}$ ) (a) e as relações entre carbono orgânico total (COT) com carbono na fração humina $\left(\mathrm{C}_{\mathrm{H}}\right)(\mathrm{b})$, na matéria orgânica leve $\left(\mathrm{C}_{\mathrm{MOL}}\right)(\mathrm{c})$ e nas frações ácidos húmicos $\left(\mathrm{C}_{\mathrm{AH}}\right)(\mathrm{d})$ e ácidos fúlvicos $\left(\mathrm{C}_{\mathrm{AF}}\right)(\mathrm{e})$ de um Neossolo Quartzarênico, em diferentes áreas de cultivo de soja e milheto, em quatro profundidades de amostragem $(\mathbf{n}=96)$. ***: $\mathbf{p}<0,001$. 


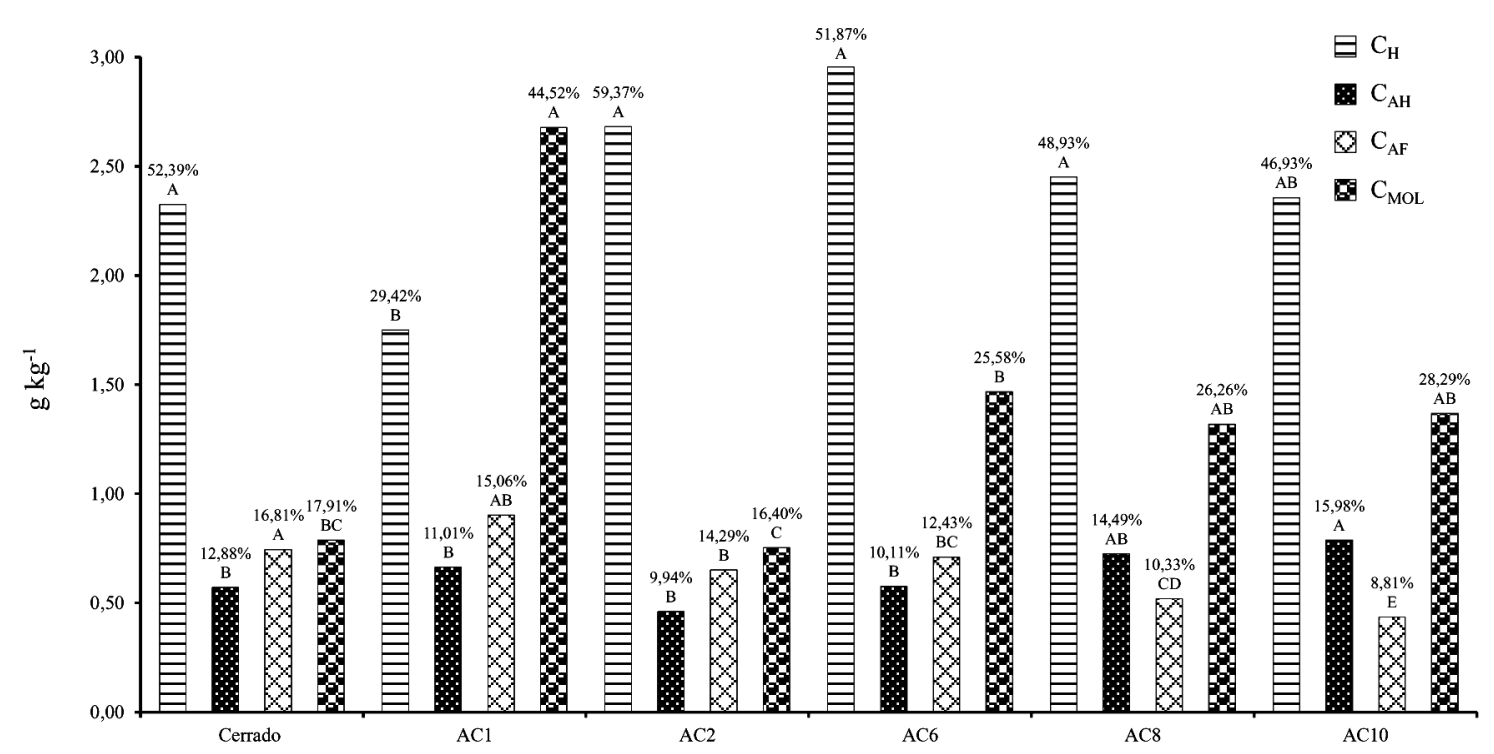

Figura 3. Distribuição de carbono na forma de humina $\left(C_{H}\right)$, carbono na forma de ácidos húmicos $\left(C_{A H}\right)$, carbono na forma de ácidos fúlvicos $\left(\mathrm{C}_{\mathrm{AF}}\right)$ e carbono na forma de matéria orgânica leve $\left(\mathrm{C}_{\mathrm{MOL}}\right)$, na profundidade de 0-20 cm de um Neossolo Quartzarênico, em diferentes áreas de cultivo de soja e milheto. AC1: área de cultivo com um ano, AC2: área de cultivo com dois anos, AC6: área de cultivo com seis anos, AC8: área de cultivo com oito anos, e AC10: área de cultivo com 10 anos. Médias não seguidas pela mesma letra maiúscula, entre as épocas e para cada fração, diferem estatisticamente entre si pelo teste MannWhitney a $5 \%$.

pela queima da vegetação nativa e aceleração da decomposição da MOS pelo revolvimento inicial do solo (Silva et al., 1994). Em solos sob vegetação nativa, quando convertidos para agricultura, a perda inicial de MOS seguida do desmatamento ocorre principalmente pela carência de matéria orgânica lábil ou carbono orgânico ativo (Brown et al., 1994). Apesar de as áreas amostradas serem conduzidas sob cultivo que causa movimentação do solo, essas não apresentaram perdas de COT até aos 10 anos de cultivo. Isso pode ser explicado porque a substituição do plantio convencional pelo plantio direto tem ocasionado a elevação da quantidade de COT em solos arenosos, resultante do aporte de carbono da palhada residual das culturas, conforme constatado por Dieckow et al. (2009). Frazão et al. (2010b) observaram a manutenção nos estoques de COT de um RQ nas áreas de soja com até cinco anos de implantação, conduzidas sob plantio direto, quando comparadas à área sob Cerrado. O cultivo contínuo de milheto como planta de cobertura de inverno nas áreas avaliadas favoreceu a manutenção dos teores de MOS. Essa cultura tem como características alta produção de matéria seca de parte aérea, sistema radicular volumoso e profundo (Gonçalves et al., 2006), além de tolerância à seca e adaptação a solos arenosos (Marteau et al., 2011).

A elevação da $\delta^{13} \mathrm{C}$, que passou a ser menos negativa, ao longo do tempo de cultivo, também indicou o aumento gradual de resíduos de plantas $\mathrm{C} 4$ por causa do aporte de biomassa pelo milheto (Quadro 3). Como a $\delta^{13} \mathrm{C}$ da soja está em torno de $-26 \%$ e do milheto em torno de $-13 \%$, os valores de $\delta^{13} \mathrm{C}$ da MOS indicaram que foi essa constituída por uma mistura de materiais originados da decomposição dos restos da vegetação nativa e da soja (plantas C3) e, com os sucessivos cultivos, o acúmulo preferencial de $\mathrm{C}$ derivado de milheto (C4), com menor participação da soja. Jantalia et al. (2007) também observaram essa elevação da $\delta^{13} \mathrm{C}$, até na camada de $40 \mathrm{~cm}$ de profundidade, que inicialmente apresentavam valores entre $-23,00 \mathrm{e}$ $-25,00 \%$, sob Cerrado nativo, e que passaram a apresentar $-21,00 \%$. Isso foi explicado pela presença de resíduos de milho e braquiária nas áreas sob sucessão, principalmente com soja por 20 anos de cultivo. Adicionalmente, o decréscimo da $\delta^{13} \mathrm{C}$ pode ser reflexo da contínua substituição do C-C3, derivado da vegetação de Cerrado na MOS por C-C3 derivado da soja.

$\mathrm{O}$ incremento nos teores da $\% \mathrm{C}_{\mathrm{MOL}}$ (Figura 3) na $\mathrm{AC} 1$, na camada de $0-20 \mathrm{~cm}$, foi seguido por um rápido decréscimo na $\mathrm{AC} 2$, restabelecendo para valores próximos aos do solo sob Cerrado. Observou-se, contudo, que houve alteração qualitativa da MOL, uma vez que sob Cerrado essa era composta por carvões e compostos recalcitrantes e, após sucessivos cultivos, passou a ser formada por resíduos das palhadas de soja e milheto, fato esse suportado pela menor relação $\mathrm{C} / \mathrm{N}$ da MOL, após seis anos de cultivo (Quadro 3). Alguns estudos demonstraram que determinados compartimentos da MOS são capazes de detectar mais rapidamente as mudanças nos teores de COT associadas ao manejo (Xavier et al., 2006). As reduções nesses compartimentos são, de modo geral, maiores 
Quadro 3. Carbono orgânico total (COT), carbono total (CT), razão isotópica do C ( $\delta^{13}$ C), relação CT/COT, nitrogênio total (NT), relação COT/NT, relação entre frações dos ácidos húmicos e ácidos fúlvicos $\left(\mathrm{C}_{\mathrm{AH}} /\right.$ $\left.\mathrm{C}_{\mathrm{AF}}\right)$, carbono da matéria orgânica leve $\left(\mathrm{C}_{\mathrm{MOL}}\right)$ e relação entre carbono e nitrogênio da matéria orgânica leve $\left(\mathrm{C} / \mathrm{N}_{\mathrm{MOL}}\right)$ de um Neossolo Quartzarênico, em diferentes áreas de cultivo de soja e milheto, em quatro profundidades

\begin{tabular}{|c|c|c|c|c|c|c|}
\hline \multirow{2}{*}{ Prof. } & \multirow[b]{2}{*}{ Cerrado } & \multicolumn{5}{|c|}{ Área de cultivo ${ }^{(1)}$} \\
\hline & & AC1 & AC2 & AC6 & AC8 & AC10 \\
\hline \multicolumn{7}{|l|}{$\mathrm{cm}$} \\
\hline & \multicolumn{6}{|c|}{$\operatorname{COT}\left(\mathrm{g} \mathrm{kg}^{-1}\right)$} \\
\hline $0-5$ & $7,08 \mathrm{~A}$ & $6,91 \mathrm{~A}$ & $6,38 \mathrm{~A}$ & $7,84 \mathrm{~A}$ & $6,91 \mathrm{~A}$ & $6,67 \mathrm{~A}$ \\
\hline $0-10$ & $5,90 \mathrm{~B}$ & $7,45 \mathrm{~A}$ & $6,05 \mathrm{AB}$ & $7,35 \mathrm{~A}$ & $6,88 \mathrm{~A}$ & $6,49 \mathrm{AB}$ \\
\hline $0-20$ & 4,84 B & $6,90 \mathrm{~A}$ & $5,14 \mathrm{~B}$ & $6,32 \mathrm{AB}$ & $5,72 \mathrm{AB}$ & $5,59 \mathrm{AB}$ \\
\hline \multirow[t]{2}{*}{$0-40$} & $3,90 \mathrm{~B}$ & $5,22 \mathrm{~A}$ & $4,17 \mathrm{~B}$ & $4,66 \mathrm{AB}$ & $4,27 \mathrm{~B}$ & $4,28 \mathrm{AB}$ \\
\hline & \multicolumn{6}{|c|}{$\mathrm{CT}\left(\mathrm{g} \mathrm{kg}^{-1}\right)$} \\
\hline $0-5$ & $8,58 \mathrm{AB}$ & $9,55 \mathrm{~A}$ & $5,48 \mathrm{~B}$ & $8,40 \mathrm{AB}$ & $9,05 \mathrm{~A}$ & $10,00 \mathrm{~A}$ \\
\hline $0-10$ & $7,31 \mathrm{AB}$ & $9,23 \mathrm{~A}$ & $4,89 \mathrm{~B}$ & $9,48 \mathrm{~A}$ & $8,86 \mathrm{~A}$ & $9,45 \mathrm{~A}$ \\
\hline $0-20$ & $6,32 \mathrm{BC}$ & $7,59 \mathrm{AB}$ & $5,52 \mathrm{C}$ & $8,03 \mathrm{~A}$ & $7,46 \mathrm{AB}$ & $7,98 \mathrm{AB}$ \\
\hline \multirow[t]{2}{*}{$0-40$} & $5,39 \mathrm{~B}$ & $8,89 \mathrm{~A}$ & $6,46 \mathrm{~B}$ & $6,25 \mathrm{~B}$ & $5,53 \mathrm{~B}$ & $6,03 \mathrm{~B}$ \\
\hline & \multicolumn{6}{|c|}{$\delta^{13} \mathrm{C}(\% \circ)$} \\
\hline $0-5$ & $-21,52 \mathrm{AB}$ & $-23,52 \mathrm{~A}$ & $-18,78$ B & $-20,70 \mathrm{~B}$ & $-20,54 \mathrm{~B}$ & $-20,01 \mathrm{~B}$ \\
\hline $0-10$ & $-21,19 \mathrm{AB}$ & $-23,91 \mathrm{~A}$ & $-18,79$ B & $-21,11 \mathrm{AB}$ & $-20,66$ B & $-20,01 \mathrm{~B}$ \\
\hline $0-20$ & $-21,15 \mathrm{AB}$ & $-23,76 \mathrm{~A}$ & $-19,11 \mathrm{~B}$ & $-21,14 \mathrm{AB}$ & $-20,74 \mathrm{~B}$ & $-19,96$ B \\
\hline \multirow[t]{2}{*}{$0-40$} & $-20,99 \mathrm{ABC}$ & $-22,93 \mathrm{~A}$ & $-19,01 \mathrm{C}$ & $-20,64 \mathrm{ABC}$ & $-20,20 \mathrm{BC}$ & $-19,75 \mathrm{BC}$ \\
\hline & \multicolumn{6}{|c|}{$\mathrm{CT} / \mathrm{COT}$} \\
\hline $0-5$ & $1,22 \mathrm{ABC}$ & $1,40 \mathrm{~A}$ & $0,85 \mathrm{C}$ & $1,06 \mathrm{BC}$ & $1,32 \mathrm{AB}$ & $1,52 \mathrm{~A}$ \\
\hline $0-10$ & $1,24 \mathrm{~A}$ & $1,25 \mathrm{~A}$ & $0,80 \mathrm{~B}$ & $1,29 \mathrm{~A}$ & $1,29 \mathrm{~A}$ & $1,49 \mathrm{~A}$ \\
\hline $0-20$ & $1,31 \mathrm{AB}$ & $1,11 \mathrm{AB}$ & $1,09 \mathrm{~B}$ & $1,27 \mathrm{AB}$ & $1,30 \mathrm{AB}$ & $1,44 \mathrm{~A}$ \\
\hline \multirow[t]{2}{*}{$0-40$} & $1,39 \mathrm{AB}$ & $1,71 \mathrm{~A}$ & $1,56 \mathrm{AB}$ & $1,35 \mathrm{AB}$ & $1,30 \mathrm{~B}$ & $1,42 \mathrm{AB}$ \\
\hline & \multicolumn{6}{|c|}{ NT $\left(\mathrm{g} \mathrm{kg}^{-1}\right)$} \\
\hline $0-5$ & $0,48 \mathrm{~B}$ & $0,46 \mathrm{~B}$ & $0,46 \mathrm{~B}$ & $0,66 \mathrm{~A}$ & $0,59 \mathrm{AB}$ & $0,57 \mathrm{AB}$ \\
\hline $0-10$ & $0,43 \mathrm{~B}$ & $0,46 \mathrm{~B}$ & $0,44 \mathrm{~B}$ & $0,57 \mathrm{AB}$ & $0,58 \mathrm{~A}$ & $0,53 \mathrm{AB}$ \\
\hline $0-20$ & $0,35 \mathrm{~B}$ & $0,43 \mathrm{AB}$ & $0,38 \mathrm{AB}$ & $0,48 \mathrm{~A}$ & $0,47 \mathrm{~A}$ & $0,46 \mathrm{AB}$ \\
\hline \multirow[t]{2}{*}{$0-40$} & $0,30 \mathrm{~A}$ & $0,35 \mathrm{~A}$ & $0,30 \mathrm{~A}$ & $0,35 \mathrm{~A}$ & $0,34 \mathrm{~A}$ & $0,33 \mathrm{~A}$ \\
\hline & \multicolumn{6}{|c|}{$\mathrm{COT} / \mathrm{NT}$} \\
\hline $0-5$ & $14,70 \mathrm{~A}$ & $15,18 \mathrm{~A}$ & $13,75 \mathrm{~A}$ & $11,87 \mathrm{~B}$ & $11,88 \mathrm{AB}$ & $11,74 \mathrm{~B}$ \\
\hline $0-10$ & $13,81 \mathrm{~B}$ & $16,09 \mathrm{~A}$ & $13,59 \mathrm{~B}$ & $12,94 \mathrm{~B}$ & $11,84 \mathrm{~B}$ & $12,23 \mathrm{~B}$ \\
\hline $0-20$ & $13,89 \mathrm{~B}$ & $16,11 \mathrm{~A}$ & $13,56 \mathrm{BC}$ & $13,29 \mathrm{BC}$ & $12,29 \mathrm{C}$ & $12,16 \mathrm{C}$ \\
\hline \multirow[t]{2}{*}{$0-40$} & $12,82 \mathrm{~A}$ & $15,16 \mathrm{~A}$ & $13,89 \mathrm{~A}$ & $13,39 \mathrm{~A}$ & $12,60 \mathrm{C}$ & $12,90 \mathrm{~A}$ \\
\hline & \multicolumn{6}{|c|}{$\mathrm{C}_{\mathrm{AH}} / \mathrm{C}_{\mathrm{AF}}$} \\
\hline $0-5$ & $0,96 \mathrm{~B}$ & $0,73 \mathrm{~B}$ & $0,97 \mathrm{AB}$ & $0,99 \mathrm{AB}$ & $1,61 \mathrm{~A}$ & $1,48 \mathrm{~A}$ \\
\hline $0-10$ & 0,93 B & $0,70 \mathrm{~B}$ & $0,83 \mathrm{~B}$ & $0,96 \mathrm{~B}$ & $1,64 \mathrm{~A}$ & $1,56 \mathrm{~A}$ \\
\hline $0-20$ & $0,77 \mathrm{C}$ & $0,74 \mathrm{C}$ & $0,69 \mathrm{C}$ & $0,82 \mathrm{C}$ & $1,42 \mathrm{~B}$ & $1,81 \mathrm{~A}$ \\
\hline \multirow[t]{2}{*}{$0-40$} & $0,68 \mathrm{~B}$ & $0,69 \mathrm{~B}$ & $0,69 \mathrm{~B}$ & $0,68 \mathrm{~B}$ & $1,24 \mathrm{~A}$ & $1,36 \mathrm{~A}$ \\
\hline & \multicolumn{6}{|c|}{$\mathrm{C}_{\mathrm{MOL}}\left(\mathrm{g} \mathrm{kg}^{-1}\right)$} \\
\hline $0-5$ & $1,68 \mathrm{BC}$ & $3,16 \mathrm{~A}$ & $1,16 \mathrm{C}$ & $2,64 \mathrm{AB}$ & $2,19 \mathrm{AB}$ & $1,87 \mathrm{ABC}$ \\
\hline $0-10$ & $1,15 \mathrm{C}$ & $2,78 \mathrm{~A}$ & $1,04 \mathrm{C}$ & $2,08 \mathrm{AB}$ & $1,91 \mathrm{AB}$ & $1,69 \mathrm{ABC}$ \\
\hline $0-20$ & $0,70 \mathrm{C}$ & $2,60 \mathrm{~A}$ & $0,75 \mathrm{C}$ & $1,47 \mathrm{~A}$ & $1,32 \mathrm{AB}$ & $1,37 \mathrm{AB}$ \\
\hline \multirow[t]{2}{*}{$0-40$} & $0,43 \mathrm{C}$ & $1,44 \mathrm{~A}$ & $0,43 \mathrm{C}$ & $0,86 \mathrm{AB}$ & $0,72 \mathrm{~B}$ & $0,86 \mathrm{AB}$ \\
\hline & \multicolumn{6}{|c|}{$\mathrm{C} / \mathrm{N}_{\mathrm{MOL}}$} \\
\hline $0-5$ & $53,34 \mathrm{~A}$ & $31,99 \mathrm{~A}$ & $20,59 \mathrm{~B}$ & $16,56 \mathrm{BC}$ & $15,42 \mathrm{C}$ & $17,76 \mathrm{BC}$ \\
\hline $0-10$ & $64,18 \mathrm{~A}$ & 32,76 B & $23,61 \mathrm{C}$ & $16,57 \mathrm{D}$ & $16,54 \mathrm{D}$ & $17,16 \mathrm{D}$ \\
\hline $0-20$ & $66,81 \mathrm{~A}$ & $32,56 \mathrm{~B}$ & $27,89 \mathrm{BC}$ & $18,37 \mathrm{C}$ & $19,19 \mathrm{C}$ & $18,36 \mathrm{C}$ \\
\hline $0-40$ & $53,26 \mathrm{~A}$ & $37,07 \mathrm{AB}$ & $32,09 \mathrm{~B}$ & $23,01 \mathrm{BC}$ & $22,50 \mathrm{BC}$ & $22,04 \mathrm{C}$ \\
\hline
\end{tabular}

(1) $\mathrm{AC} 1$ : área de cultivo com um ano, AC2: área de cultivo com dois anos, AC6: área de cultivo com seis anos, AC8: área de cultivo com oito anos, e AC10: área de cultivo com 10 anos. Médias seguidas pela mesma letra na linha, não diferem estatisticamente entre si pelo teste Mann-Whitney a $5 \%$. 
que as observadas, quando se considera apenas o teor total de COT (Bayer et al., 2004); a MOL representa uma medida de sensibilidade intermediária nessa detecção (Freixo et al., 2002a). A MOL pode ser considerada como compartimento de decomposição lenta da MOS, considerando a dinâmica do C e N no solo (Leite et al., 2003). A sua manutenção torna-se fundamental para a sustentabilidade agrícola, pois representa, em curto e médio prazo, potencial para ciclagem de nutrientes (Compton \& Boone, 2002). Os resultados deste trabalho são diferentes daqueles verificados por Frazão et al. (2010b) e Zinn et al. (2002), em que o uso dos RQs reduziu as quantidades de $\mathrm{C}_{\mathrm{MOL}}$, demonstrando que o manejo utilizado foi fundamental para a sustentabilidade desse sistema, em relação a outros observados em solos arenosos.

A quantificação das substâncias húmicas de maior mobilidade e estabilidade demonstraram aspectos da dinâmica de $\mathrm{C}$ que não puderam ser observados pela simples análise dos teores de COT. Os sucessivos anos de cultivo de soja e milheto causaram o aumento do $\% \mathrm{C}_{\mathrm{AH}}$ e a redução do $\% \mathrm{C}_{\mathrm{AF}}$, na camada de $0-20 \mathrm{~cm}$ (Figura 3). Observando-se a relação $\mathrm{C}_{\mathrm{AH}} / \mathrm{C}_{\mathrm{AF}}$, isso ficou melhor evidenciado, pois houve o seu aumento no longo do tempo de cultivo (Quadro 3). Esse resultado indica a perda seletiva da fração solúvel ácido fúlvico, que foi mineralizada e, ou, lixiviada para a subsuperfície, causando perdas de carbono nesse RQ. A perda dessa fração em profundidade foi verificada por Cunha et al. (2001) em um Latossolo Vermelho-Amarelo de textura média e pode ocorrer principalmente em solos arenosos, que têm maior predisposição a essas perdas. Os resultados para a $\% \mathrm{C}_{\mathrm{AH}}$ elevaram-se a partir do oitavo ano de cultivo, chegando a teores superiores ao encontrados em solos sob Cerrado, indicando que está ocorrendo acúmulo de $\mathrm{C}$ na forma de $\mathrm{AH}$ no longo do tempo de cultivo (Figura 3).

\section{CONCLUSÕES}

1. Os atributos da matéria orgânica do solo, determinados na camada de $0-20 \mathrm{~cm}$, representaram melhor as alterações no manejo dos Neossolos Quartzarênicos do que os determinados em outras camadas de solo.

2. O cultivo de soja em sucessão ao milheto foi capaz de manter inalterado o estoque de carbono do solo, mas causou alterações na qualidade da MOS.

3. A palhada do milheto foi a principal responsável pela manutenção dos teores de carbono no solo, ao longo do tempo, conforme indicado pelo aumento da $\delta^{13} \mathrm{C}$.

4. A fração ácido fúlvico e a matéria orgânica leve foram mais sensíveis às alterações causadas pelo cultivo agrícola desses solos do que o carbono orgânico total.
5. O aumento da relação entre ácido húmico e fúlvico demonstrou perda seletiva de compostos orgânicos de maior solubilidade.

\section{AGRADECIMENTO}

À Sementes Adriana Ltda., pelo auxílio financeiro à esta pesquisa por meio de convênio com a Universidade de Rio Verde.

\section{LITERATURA CITADA}

ARAÚJO, R.; GOEDERT, W.J. \& LACERDA, M.P.C. Qualidade de um solo sob diferentes usos e sob Cerrado nativo. R. Bras. Ci. Solo, 31:1099-1108, 2007.

BATLLE-BAYER, L.; BATJES, N.H. \& BINDRABAN, P.S. Changes in organic carbon stocks upon land use conversion in the Brazilian Cerrado: A review. Agric. Ecosyst. Environ., 137:47-58, 2010.

BAYER, C.; MARTIN-NETO, L.; MIELNICZUK, J. \& PAVINATO, A. Armazenamento de carbono em frações lábeis da matéria orgânica de um Latossolo Vermelho sob plantio direto. Pesq. Agropec. Bras., 39:677-683, 2004.

BENITES, V.M.; MADARI, B. \& MACHADO, P.L.O.A. Extração e fracionamento quantitativo de substâncias húmicas do solo: um procedimento simplificado de baixo custo. Rio de Janeiro, Embrapa Solos, 2003. 7p. (Comunicado Técnico, 16)

BOER, C.A.; ASSIS, R.L.; SILVA, G.P.; BRAZ, A.J.B.P.; BARROSO, A.L.L.; CARGNELUTTI FILHO, A. \& PIRES, F.R. Ciclagem de nutrientes por plantas de cobertura na entressafra em um solo de cerrado. Pesq. Agropec. Bras., 42:1269-1276, 2007.

BREMNER, J.M. \& MULVANEY, C.S. Nitrogen total. In: PAGE, A.L.;MILLER, R.H. \& KEENEY, D.R., eds. Methods of soil analysis. 2.ed. Madison, American Society of Agronomy, 1982. p.595-624.

BROWN, S.; ANDERSON, J.; WOOMER, P.; SWIFT, M. \& BARRIOS, E. Soil biological processes in tropical ecosystems. In: WOOMER, P.L. \& SWIFT, M.J., eds. The biological management of tropical soil fertility. Chichester, Wiley, 1994. p.15-46.

CAETANO, J.O. Caracterização de atributos químicos e físicos de um Neossolo Quartzarênico sob diferentes tempos de cultivo com soja e milheto. Rio Verde, Universidade de Rio Verde, 2006. 160p. (Dissertação de Mestrado)

CAMPOS, L.P.; LEITE, L.F.C.; MACIEL, G.A.; IWATA, B.F. \& NÓBREGA, J.C.A. Atributos químicos de um Latossolo Amarelo sob diferentes sistemas de manejo. Pesq. Agropec. Bras., 46:1681-1689, 2011.

CARNEIRO, M.A.C.; SOUZA, E.D.; REIS, E.F.; PEREIRA, H.S. \& AZEVEDO, W.R. Atributos físicos, químicos e biológicos de solo de Cerrado sob diferentes sistemas de uso e manejo. R. Bras. Ci. Solo, 33:147-157, 2009. 
CHIVENGE, P.P.; MURWIRA, H.K.; GILLER, K.E.; MAPFUMO, P. \& SIX, J. Long-term impact of reduced tillage and residue management on soil carbon stabilization: Implications for conservation agriculture on contrasting soils. Soil Till. Res., 94:328-337, 2007.

COMPTON, J.E. \& BOONE, R.D. Soil nitrogen transformations and the role of light fraction organic matter in forest soils. Soil Biol. Biochem., 34:933-943, 2002.

CORAZZA, E.J; SILVA, J.E; RESCK, D.V.S. \& GOMES, A.C. Comportamento de diferentes sistemas de manejo como fonte ou depósito de carbono em relação à vegetação de Cerrado. R. Bras. Ci. Solo, 23:425-432, 1999.

CUNHA, T.J.F.; MACEDO, J.R.; RIBEIRO, L.P.; PALMIERI, F.; FREITAS, P.L. \& AGUIAR, A.C. Impacto do manejo convencional sobre propriedades físicas e substâncias húmicas de solos sob Cerrado. Ci. Rural, 31:27-36, 2001.

DIECKOW, J.; BAYER, C.; CONCEIÇÃO, P.C.; ZANATTA, J.A.; MARTIN-NETO, L.; MILORI, D.B.M.; SALTON, J.C.; MACEDO, M.M.; MIELNICZUK, J. \& HERNANI, L.C. Land use, tillage, texture and organic matter stock and composition in tropical and subtropical Brazilian soils. Eur. J. Soil Sci., 60:240-249, 2009.

EMPRESA BRASILEIRA DE PESQUISA AGROPECUÁRIA EMBRAPA. Sistema brasileiro de classificação de solos. 2.ed. Rio de Janeiro, 2006. 306p.

FRAZÃO, L.A.; PICCOLO, M.C.; FEIGL, B.J.; CERRI, C.C. \& CERRI, C.E.P. Inorganic nitrogen, microbial biomass and microbial activity of a sandy Brazilian Cerrado soil under different land uses. Agric. Ecosyst. Environ., 135:161$167,2010 \mathrm{a}$

FRAZÃO, L.A.; SANTANA, I.K.S.; CAMPOS, D.V.B.; FEIGL, B.J. \& CERRI, C.C. Estoques de carbono e nitrogênio e fração leve da matéria orgânica em Neossolo Quartzarênico sob uso agrícola. Pesq. Agropec. Bras., 45:1198-1204, 2010b.

FRAZÃO, L.A.; PÍCCOLO, M.C.; FEIGL, B.J.; CERRI, C.C. \& CERRI, C.E.P. Propriedades químicas de um Neossolo Quartzarênico sob diferentes sistemas de manejo no Cerrado Mato-Grossense. Pesq. Agropec. Bras., 43:641648, 2008.

FREIXO, A.; MACHADO, P.; GUIMARAES, C.; SILVA, C. \& FADIGAS, F.S. Estoques de carbono e nitrogênio e distribuição de frações orgânicas de Latossolo do Cerrado sob diferentes sistemas de cultivo. R. Bras. Ci. Solo, 26:425-434, 2002a.

FREIXO, A.A.; MACHADO, P.L.O.A.; SANTOS, H.P.; SILVA, C.A. \& FADIGAS, F.S. Soil organic carbon and fractions of a Rhodic Ferralsol under the influence of tillage and crop rotation systems in southern Brazil. Soil Till. Res., 64:221-230, 2002b.

GONÇALVES, W.G.; JIMENEZ, R.L.; ARAÚJO FILHO, J.V.; ASSIS, R.L.; SILVA, G.P. \& PIRES, F.R. Sistema radicular de plantas de cobertura sob compactação do solo. Eng. Agric., 26:67-75, 2006.

JANTALIA, C.P.; RESCK, D.V.S.; ALVES, B.J.R.; ZOTARELLI, L.; URQUIAGA, S. \& BODDEY, R.M. Tillage effect on C stocks of a clayey Oxisol under a soybean-based crop rotation in the Brazilian Cerrado region. Soil Till. Res., 95:97-109, 2007.
LEITE, L.F.C.; MENDONCA, E.S.; MACHADO, P.L.O.A. \& MATOS, E.S. Total $\mathrm{C}$ and $\mathrm{N}$ storage and organic $\mathrm{C}$ pools of a Red-Yellow Podzolic under conventional and no tillage at the Atlantic Forest Zone, Southeastern Brazil. Aust. J. Soil Res., 41:717-730, 2003.

MARTEAU, R.; SULTAN, B.; MORON, V.; ALHASSANE, A.; BARON, C. \& TRAORÉ, S.B. The onset of the rainy season and farmers' sowing strategy for pearl millet cultivation in Southwest Niger. Agric. For. Meteorol., 151:1356-1369, 2011.

MASCARENHAS, H.A.A.; ESTEVES, J.A.F.; WUTKE, E.B. \& LEÃO, P.C.L. Nitrogênio residual da soja na produtividade de gramíneas e do algodão. Nucleus, 8:15-34, 2011.

SALES, L.E.O.; CARNEIRO, M.A.C.; SEVERIANO, E.C.; OLIVEIRA, G.C. \& FERREIRA, M.M. Qualidade física de Neossolo Quartzarênico submetido a diferentes sistemas de uso agrícola. Ci. Agrotec., 34:667-674, 2010.

SILVA, I.R. \& MENDONÇA, E.S. Matéria orgânica do solo. In: NOVAIS, R.F.; ALVAREZ V., V.H.; BARROS, N.F.; FONTES, R.L.F.; CANTARUTTI, R.B. \& NEVES, J.C.L., eds. Fertilidade do solo. Viçosa, MG, Sociedade Brasileira de Ciência do Solo, 2007. p.275-374.

SILVA, J.E.; LEMAINSKI, J. \& RESCK, D.V.S. Perdas de matéria orgânica e suas relações com a capacidade de troca catiônica em solos da Região de Cerrados do Oeste Baiano. R. Bras. Ci. Solo, 18:541-547, 1994.

SOHI, S.P.; MAHIEU, N.; ARAH, J.R.M.; POWLSON, D.S.; MADARI, B. \& GAUNT, J.L. A procedure for isolating soil organic matter fractions suitable for modeling. Soil Sci. Soc. Am. J., 65:1121-1128, 2001.

STATSOFT Inc. Statistica (data analysis software system). Version 7.0, 2008.

WILCKE, W. \& LILIENFEIN, J. Soil carbon-13 natural abundance under native and managed vegetation in Brazil. Soil Sci. Soc. Am. J., 68:827-832, 2004.

XAVIER, F.A.S.; MAIA, S.M.F.; OLIVEIRA, T.S. \& MENDONÇA, E.S. Biomassa microbiana e matéria orgânica leve em solos sob sistemas agrícolas orgânico e convencional na chapada da Ibiapaba - CE. R. Bras. Ci. Solo, 30:247-258, 2006

YEOMANS, J.C. \& BREMNER, J.M. A rapid and precise method for routine determination of organic carbon in soil. Commun. Soil Sci. Plant Anal., 19:1467-1476, 1988.

ZINN, Y.L.; LAL, R.; BIGHAM, J.M. \& RESCK, D.V.S. Edaphic controls on soil organic carbon retention in the Brazilian Cerrado: Texture and mineralogy. Soil Sci. Soc. Am. J., 71:1204-1214, 2007.

ZINN, Y.L.; LAL, R. \& RESCK, D.V.S. Changes in soil organic carbon stocks under agriculture in Brazil. Soil Till. Res., $84: 28-40,2005 a$.

ZINN, Y.L.; LAL, R. \& RESCK, D.V.S. Texture and organic carbon relations described by pedotransfer function for Brazilian Cerrado. Geoderma, 127:168-173, 2005b.

ZINN, Y.L.; RESCK, D.V.S. \& SILVA, J.E. Soil organic carbon as affected by afforestation with eucalyptus and pinus in the Cerrado Region of Brazil. For. Ecol. Manage., 166:285$294,2002$. 